\title{
Evaluation of Caesalpinia Pulcherrima Endospermic Gum as Affinity Matrices for Galactose-Binding Lectins Interaction
}

\author{
Renata Chastinet Braga*, Daniele Maria Alves Teixeira-Sá, Alexsandra Feitosa Ribeiro, \\ Raquel Lima Miranda, Lia Magalhães de Almeida, Ana Cecília Góes Horta and Renato de \\ Azevedo Moreira \\ Departamento de Bioquímica e Biologia Molecular; Universidade Federal do Ceará; Av. Mister Hull s/n; \\ 60451980; Fortaleza - CE - Brasil
}

\begin{abstract}
Lectins are proteins or glycoproteins able to bind, specifically and reversibly carbohydrates and glycoconjugates. Considering this ability, the utilization of Caesalpinia pulcherrima seeds polysaccharides as an affinity matrix was tested. The endospermic gum were solubilized in distinct concentrations of $\mathrm{NaOH}$ and treated with different amounts of epichlorohydrin (ECH) forming affinity gels with variable capacity for interaction with galactosebinding lectins. The gel with an ECH/gum ration of $6.0 \mathrm{mmol} / \mathrm{g}$ was selected as the best affinity matrix. The matrix presented different efficiencies in terms of isolating galactose-binding lectins. C. pulcherrima endospermic galactomannans were purified by ethanol precipitation and the purified galactomannan was crosslinked with the best formulation of gel. The Artocarpus incisa, Ricinus communis and Abrus precatorius lectins showed interactions of 11.5, 17.7 and 47.2mg of retained protein in $1 \mathrm{~g}$ of gel, respectively; the Artocarpus integrifolia lectin showed the highest affinities $(79.7 \mathrm{mg} / \mathrm{g})$. The heamaglutination assays confirmed the activity and SDS-PAGE electrophoresis confirmed the isolation of the lectins in a single-step procedure.
\end{abstract}

Key words: galactose binding lectins, affinity chromatography, galactomannans

\section{INTRODUCTION}

Lectins are known as glycocodes deciphers (Nangia-Makker, et al., 2002). Lectin specificity is usually defined according to the mono- or oligosaccharide that is able to inhibit the agglutinating activity induced by the lectin (Souza et al., 2005). Lectins are able to recognize and binding specifically carbohydrate and glycoconjugates. This characteristic makes them excellent tools in biotechnology (Lima et al., 2002). New lectins have been reported each year and applied in diverse areas (Vasconcelos and Oliveira, 2004).
Since 1965, when Agrawal and Goldstein isolated Concanavalin A (ConA) by affinity chromatography on Sephadex, this procedure has been considered as the best method for lectin purification. This technique uses lectin properties to bind, with high affinity and specificity, carbohydrates or glycoconjugates. In 1975, Fujita et al., the pioneer scientists using plant polysaccharides as affinity matrices, isolated Streptomyces anti-B Hemaglutinin with an arabic gum matrix. Following their studies, Appukutan et al. (1977) prepared an affinity matrix with guar gum and isolated a Ricinus communis lectin.

*Author for correspondence: r_chastinet@hotmail.com 
Lima et al. (2002) and Teixeira et al. (2007) succeeded using natural exudates gums from Anacardium occidentale and Spondias purpurea, respectively to purify lectins. From some seed galactomannans (Moreira et al., 1998, GarrosRosa et al., 2006, Seshagirirao et al., 2005) new matrices showed the ability to isolate galactosebinding lectins with different efficiencies.

The studies performed with exudates gums have compared the diverse formulations to form the affinity matrix while, until now, the endospermic studies have cited only one preparation for each galactomannan. Therefore, the aim of this work was to compare different formulations used to make an affinity matrix, the main component being seed galactomannans.

Carbohydrates are stored either as starch grains or hemicellulosic wall thickening, which are common in the endosperm and cotyledons (Teixeira and Machado, 2008). Seed galactomannans are polysaccharides widely distributed in nature. They have attracted considerable academic attention as well as industrial interest due to their property of forming viscous solutions in water (Srivasta and Kapoor, 2005).

In 1987, Chowdhury and Chatterjee used the jacalin galactose-binding lectin to isolate Caesalpinia pulcherrima galactomannans. This procedure showed a good interaction between this seed galactomannans and the jacalin. The $C$. pulcherrima seeds show an endospermic gum, mainly comprising galactomannans. The galactomananns are based on a $\beta$-D- $(1 \rightarrow 4)$ mannose unit polymeric backbone, with side groups consisting of a $(1 \rightarrow 6)$ linked $\alpha$-D-galactose unit. The main difference between galactomannans is their mannose to galactose ratio $(\mathrm{M} / \mathrm{G})$ and the sequential distribution of galactopyranosyl substituents on the mannopyranosyl backbone. In C. pulcherrima endospermic gum, the $\mathrm{M} / \mathrm{G}$ ratio is 2.8 (Andrade et al., 1999), but the sequential distribution of the galactopyranosyl unit is unclear. C. pulcherrima, a small tree known, as Pride of Barbados, "flamboianzinho", "flaboiant mirim", "barba de barata" and "brado de estudante", is widely used in many countries in popular medicine, showing many properties, including its use as an emmenagogue, antihemorrhagic agent and abortifacient and also in the treatment of infections (Alanis et al., 2005, Chiang et al., 2003, Patil et al., 1997). It is also greatly appreciated for its ornamental qualities with yellow, red, orange and pink flowers (Owens et al., 1995). The tree is common throughout the Northeast coastal regions of Brazil, being easy to plant and to grow. Since this species produces a large amount of seeds, it could provide a new source to produce affinity matrices. Thus, the aim of this work was to investigate some ways to formulate the affinity matrices from $C$. pulcherrima galactomannan, and then test the specificity and ability to bind lectins.

\section{MATERIALS AND METHODS}

\section{Materials}

The seeds of Caesalpinia pulcherrima were collected from the trees in the experimental field of the Federal University of Ceará. The Artocarpus incisa, Artocarpus integrifolia, Abrus precatorius, Ricinus communis and Canavalia maritima seeds were obtained from Maranguape in Ceará, Brazil. A voucher specimen of the seeds of $C$. pulcherrima has been deposited in the Herbarium Prisco Bezerra - EAC (UFC) under the number 44718.

\section{Endosperm separation and characterization}

The $C$. pulcherrima seeds were submitted to heating in boiling water for 10 minutes. The endosperm was obtained by manual separation, freeze dried and homogenized. This material was denominated endospermic gum (EG) and the samples were used to determine the amounts of lipid, protein (Kjeldahl method), moisture and ash (Triebold, 1946).

\section{Polyssaccharide isolation}

The EG was submitted to water extraction for $1 \mathrm{~h}$ and then centrifuged $(10,000 \mathrm{x} \mathrm{g}, 30 \mathrm{~min})$. The supernatant was precipitated with ethanol $(95 \%)$ (1:3); the pellet was solubilized with $\mathrm{H}_{2} \mathrm{O}$, reprecipitated in $95 \%$ ethanol (1:3), the precipitate was re-solubilized and dried in vacuum at $20^{\circ} \mathrm{C}$; this material was denominated as galactomannans.

\section{Viscosity}

Viscosities of dilute solutions were measured at 25 $\pm 0.1^{\circ} \mathrm{C}$ with a Cannon Fenske capillary viscometer (ASTM-D2515, Series 100), using 10 $\mathrm{mL}$ of solution sample. Water solutions were prepared to have relative viscosities from about 1.2-2.0 to assure good accuracy and linearity of extrapolation to zero concentration. 


\section{HPSEC analysis}

The elution profiles of $C$ pulcherrima were determined by high pressure size exclusion chromatography (HPSEC), using a Waters 510

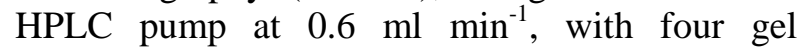
permeation columns in series with exclusion sizes of one million to five thousand. The apparatus, coupled to a differential refractometer Waters Model 2410 Wyatt Technology Dawn DFP and Multi-Angle Laser Light Scattering (MALLS) detector was used for the characterisation of the fractions. A $0.1 \mathrm{M} \mathrm{NaNO}$ 2olution, containing $\mathrm{NaN}_{3}\left(0.5 \mathrm{~g} \mathrm{l}^{-1}\right)$ was used as eluent. Samples (1 mg $\mathrm{ml}^{-1}$ ) were prepared by stirring overnight and filtered through a membrane $0.22 \mathrm{~nm}$.

\section{Monosaccharide composition}

The purified gum was hydrolyzed with 1M trifluoroacetic acid $\left(5 \mathrm{~h}, 96^{\circ} \mathrm{C}\right)$. The hydrolyzate was used to perform a thin layer chromatography (TLC). The monosaccharides were also reduced with sodium borohydride $(12 \mathrm{~h})$ at $25^{\circ} \mathrm{C}$, after the removal of the acid. The resulting alditol acetates were analyzed by gas-liquid chromatography (GLC), using Hewlett Packard 5890 A II at $220^{\circ} \mathrm{C}$ (feed and injector temperature, $250^{\circ} \mathrm{C}$ ) with DB225 capillary column and carrier gas $\mathrm{N}_{2}(2 \mathrm{ml} / \mathrm{min})$.

\section{Treatment with epichlorohydrin}

The EG was treated with epichlorohydrin (ECH) in the presence of $\mathrm{NaOH}$. To the purified polysaccharide and $\mathrm{EG}$, the $\mathrm{NaOH}$ at $40^{\circ} \mathrm{C}$ was added and, after homogenization, epiclorohydrin was mixed and vigorously stirred at $40^{\circ} \mathrm{C}$. The reaction was allowed to continue for $24 \mathrm{~h}$ at the same temperature and then the reaction temperature was raised to $70^{\circ} \mathrm{C}$. After this, the cross-linked gel was exhaustively washed with distilled water until all the fine particles in the suspension were removed. The material was homogenized and passed through a 30-mesh sieve, the fine particles being removed by exhausting washing with distilled water.

The amounts and concentrations of ECH and $\mathrm{NaOH}$ are shown in Table 1 , following a factorial, in comparison with the conditions used by Moreira et al. (1998), Lima et al. (2002), Garros-Rosa et al. (2006) and Teixeira et al. (2007). The best treatment was used to in-sobulize the galactomannans.

$\underline{\text { Table } 1 \text { - Experimental conditions applied to C. pulcherrima gel preparations }}$

\begin{tabular}{|c|c|c|c|c|c|c|c|c|}
\hline \multirow[b]{2}{*}{ Gel } & \multicolumn{3}{|c|}{ Volume and concentration used } & \multicolumn{3}{|c|}{ Final Concentration } & \multicolumn{2}{|c|}{ Ratio } \\
\hline & $\begin{array}{c}\mathrm{NaOH} \\
(\mathrm{mL})\end{array}$ & $\begin{array}{c}\mathrm{NaOH} \\
(\mathrm{M})\end{array}$ & $\begin{array}{c}\mathbf{E C H}^{\mathrm{a}} \\
(\mathbf{m L})\end{array}$ & $\begin{array}{c}\text { Gum } \\
(\mathrm{g} / \mathbf{m L})\end{array}$ & $\begin{array}{c}\mathrm{NaOH} \\
(\mathbf{M})\end{array}$ & $\begin{array}{c}\text { ECH } \\
(\mathbf{M})\end{array}$ & $\begin{array}{c}\mathrm{ECH} / \mathrm{gum} \\
\mathrm{mmol} / \mathrm{g}\end{array}$ & $\begin{array}{c}\mathbf{N a O H} / \mathbf{E C H} \\
(\mathrm{M} / \mathrm{M})\end{array}$ \\
\hline$\overline{\mathrm{A}_{1}}$ & 4.0 & 3.0 & 0.25 & 0.12 & 2.8 & 0.7 & 6.0 & 4.0 \\
\hline $\mathrm{A}_{2}$ & 4.0 & 3.0 & 0.50 & 0.11 & 2.7 & 1.4 & 12.6 & 1.9 \\
\hline $\mathrm{A}_{3}$ & 4.0 & 3.0 & 1.00 & 0.10 & 2.4 & 2.5 & 25.0 & 1.0 \\
\hline $\mathrm{A}_{4}$ & 4.0 & 3.0 & 2.00 & 0.08 & 2.0 & 4.1 & 49.2 & 0.5 \\
\hline $\mathrm{B}_{1}$ & 1.5 & 3.0 & 0.50 & 0.33 & 2.2 & 3.1 & 12.4 & 0.7 \\
\hline $\mathrm{B}_{2}$ & 3.0 & 3.0 & 0.50 & 0.14 & 2.6 & 1.8 & 12.6 & 1.4 \\
\hline $\mathrm{B}_{4}$ & 5.0 & 3.0 & 0.50 & 0.09 & 2.7 & 1.1 & 12.1 & 2.4 \\
\hline $\mathrm{C}_{1}$ & 4.0 & 1.0 & 0.50 & 0.11 & 0.9 & 1.4 & 12.6 & 0.6 \\
\hline $\mathrm{C}_{2}$ & 4.0 & 2.0 & 0.50 & 0.11 & 1.8 & 1.4 & 12.6 & 1.3 \\
\hline $\mathrm{C}_{4}$ & 4.0 & 4.0 & 0.50 & 0.11 & 3.6 & 1.4 & 12.6 & 2.6 \\
\hline
\end{tabular}

Polysaccharide was kept constant in $0.5 \mathrm{~g}$.

a concentration $12.4 \mathrm{M}$

\section{Infrared Spectrum}

Fine pulverized water-free samples of cross-linked and non cross-linked galactomannan were mixed with potassium bromide and then pressed to obtain a pellet. The spectrometer used was a 1320 PerkinElmer spectrometer working in the wave number ranger of 4000 to $400 \mathrm{~cm}^{-1}$. The final evaluation was carried out with a Fourier self deconvolution function.

\section{Lectin extraction}

The seed cotyledons were obtained by manual separation. For the Artocarpus seeds, the cotyledons were dried in acetone. All cotyledons were finely ground and extracted with $0.15 \mathrm{M}$ $\mathrm{NaCl}$ for $4 \mathrm{~h}$ at room temperature $(10 \% \mathrm{w} / \mathrm{v})$, filtered using nylon tissue and centrifuged at $10,000 \mathrm{x} \mathrm{g}$ for $30 \mathrm{~min}$ at $4^{\circ} \mathrm{C}$. The clear supernatants were then submitted to affinity chromatography. 


\section{Affinity chromatography}

The columns were constructed by leaving the cross-linked gel $(0.3 \mathrm{~g})$ to settle by gravity and equilibrated with $\mathrm{NaCl}$ at $0.15 \mathrm{M}$.

The crude seed extracts were dissolved in $0.15 \mathrm{M}$ $\mathrm{NaCl}$ and applied (3mL) to the columns, containing the affinity galactomannan matrix. The elution of the column was carried out initially with the equilibrium solution and the retained material was eluted by $0.15 \mathrm{M} \mathrm{NaCl}$ containing $0.2 \mathrm{M}$ galactose, or $0.1 \mathrm{M} \beta$-alanin $\mathrm{pH} 2.6$ buffer solutions. Elution was carried out at a constant flow rate $(30 \mathrm{~mL} / \mathrm{h})$ and the absorbance of the fractions was determined at $280 \mathrm{~nm}$. For the unretained and retained fractions, the protein content and hemagglutinating activity were determined.

\section{Hemagglutination activity}

Hemagglutination assays were performed in small glass tubes where a series of 1:2 dilutions of the samples were left to react with rabbit erythrocytes (2\%) as described by Moreira and Perrone (1977). The assay was carried out in hemagglutinating tubes and $100 \mu \mathrm{l}$ of $\mathrm{NaCl}(0.15 \mathrm{M})$ were added to each tube. In the first tube, the sample was diluted to $100 \mu \mathrm{l}$ and serial dilutions $(1: 2,1: 4,1: 8$, etc.) were then carried out with complete homogenization before each transfer. Immediately then $100 \mu \mathrm{l}$ of an erythrocyte suspension (to $2 \%$ ) was added to all wells. Agglutination was scored after $30 \mathrm{~min}$ at $37^{\circ} \mathrm{C}$ and room temperature as the reciprocal of the highest lectin dilution giving detectable agglutination $\left(\mathrm{H} . \mathrm{UmL}^{-1}\right)$ or the minimum dose (the minimum amount of lectin to promote a visible agglutination, in $\mu \mathrm{g} \mathrm{mL}^{-1}$ ).

\section{Polyacrylamide gel electrophoresis}

SDS polyacrylamide gel electrophoresis (SDSPAGE) was carried out as described by Laemmli (1970), using $15 \%$ polyacrylamide gels. Samples were dissolved in $62.5 \mathrm{mM}$ Tris- $\mathrm{HCl}(\mathrm{pH} 6.8)$ containing $2 \%$ SDS and heated at $100^{\circ} \mathrm{C}$ for $10 \mathrm{~min}$. After electrophoresis, the bands were revealed with silver (Blum et al., 1987).

\section{RESULTS AND DISCUSSION}

The $C$. pulcherrima seeds were brown, with average weight $154.8 \mathrm{mg}( \pm 10.6)$, width $6.8 \mathrm{~mm}( \pm$ $0.3)$, length $8.6 \mathrm{~mm}( \pm 0.42)$ and thickness 3.02 $\mathrm{mm} \pm 0.24$ (mean of 100 seeds). The endosperm was easy to separate manually from the cotyledon and the tegument with good yields. The endosperm represented $32.6 \%$ of the whole seed. The approximate chemical composition is shown in Table 2.

Table 2 - Chemical composition of EG

\begin{tabular}{cc}
\hline Seed & Percentage \\
\hline Moisture & 9.03 \\
Ash & 2.05 \\
Proteins & 4.44 \\
Lipids & 0.69 \\
Carbohydrates & 92.82 \\
\hline
\end{tabular}

The gum purification was obtained similar as by Azero and Andrade (2002) who obtained 99\% of galactomannans. The EG purification with ethanol reduced to $45 \%$ the protein content. The infrared spectrum of the purified gum showed similar profile of EG. The results of HPSEC showed a homogenous peak, suggesting a pure polysaccharide with molecular weight of $2.3 \mathrm{x}$ $10^{5} \mathrm{~g} \mathrm{~mol}^{-1}$.
The C. pulcherrima seeds had the chemical composition similar to that reported to others leguminosae seeds (Prakash et al., 2001; Srivasta and Kapoor, 2005). The TLC presented only two bands; one strong being in mannose position and other in galactose position. The GLC and viscosity results are shown in the Table 3 . The ratio of Manose:galactose was 3.6:1.

Table 3 - Chemical composition of EG

\begin{tabular}{ccc}
\hline Man/Gal & {$[\mathbf{\eta}]$} & $\left(\mathbf{K}_{\mathbf{H}}\right)$ \\
\hline $3.6: 1$ & $10.83 \mathrm{dL} / \mathrm{g}$ & 1.36
\end{tabular}

[y] Huggins extrapolation; $K_{H}$ Huggins coeficient. 
The infrared spectra of the EG and the crosslinked EG (Treatment $A_{1}$ ) were done. The EG spectrum showed bands similar to standard galactomannans. The result agreed with those reported by Andrade et al. (1999) and Azero and Andrade (2002). The spectra of the purified and cross-linked gum showed differences in the bands in some spectral regions. The cross-linked gum showed a decrease at $3000 \mathrm{~cm}^{-1}-3500 \mathrm{~cm}^{-1}$ and increased at $1500 \mathrm{~cm}^{-1}$. The modifications in the spectrum suggested the formation of cross-linking. The strong decrease in the $\mathrm{OH}$ stretching region $\left(3000 \mathrm{~cm}^{-1}-3500 \mathrm{~cm}^{-1}\right)$ observed was probably due to the formation of ether linkages between the epichlorohydrin and the sugar $\mathrm{OH}$, and an increase in the $\mathrm{CHCC}$ bending band $\left(1500 \mathrm{~cm}^{-1}\right)$, related to the interaction between the $\mathrm{ECH}$ and the sugar-OH (Glavechev et al., 2000).

The cross-linked gels obtained were stable to acid and alkaline conditions and used as affinity matrix for chromatographic isolation of lectins. All the quantities indicated in Table 1 were able to form the gels of high permeation. The weight of the gels obtained from $500 \mathrm{mg}$ gum in the cross-linking procedure was variable (Table 4). The final concentration of $\mathrm{ECH}$ in the reaction medium was proportional to the final weight of the matrices. This effect was to be expected since the ECH was inserted in the gum to form the matrix.

Table 4 - Final weight and weight/volume ratio in cross-linked gels. (From 500mg endospermic gum).

\begin{tabular}{ccc}
\hline Treatment & Final weight $(\mathbf{m g})$ & w/v ratio $(\mathbf{m g} / \mathbf{m L})$ \\
\hline $\mathrm{A}_{1}$ & 348 & 35.5 \\
$\mathrm{~A}_{2}$ & 383 & 31.1 \\
$\mathrm{~A}_{3}$ & 615 & 57.4 \\
$\mathrm{~A}_{4}$ & 594 & 67.9 \\
$\mathrm{~B}_{1}$ & 533 & 124.4 \\
$\mathrm{~B}_{2}$ & 459 & 45.2 \\
$\mathrm{~B}_{4}$ & 407 & 32.4 \\
$\mathrm{C}_{1}$ & 458 & 37.3 \\
$\mathrm{C}_{2}$ & 477 & 33.2 \\
$\mathrm{C}_{4}$ & 387 & 34.7 \\
\hline
\end{tabular}

In order to determine the best formulation, interactions with $A$. integrifolia and A. inicisa lectins were used. Figures 1, 2 and 3 show the chromatographic profiles for the A. integrifolia extract. When the ability to isolate the lectins was tested, column $\mathrm{A}_{2}$ was used as the intermediate formulation for comparison with the others. All the matrices indicated lower interaction with $A$. incisa lectin as seen in the graphics and in the Table 5. The A group demonstrated that the matrices with higher $\mathrm{ECH}$ concentration were more compact (higher $\mathrm{mg} / \mathrm{mL}$ ratio of gels - Table 4) and the flux was easier to control. On the other hand, the interaction with the lectins appeared to be better in the matrix with the lower volume of ECH (Table 5). The cross-linking agent (ECH) seemed to be necessary to stabilize the gel, but low concentrations were more efficient, probably because the linkage occurred at the galactose branch. Therefore, more ECH interaction meant less galactose available for the interaction.

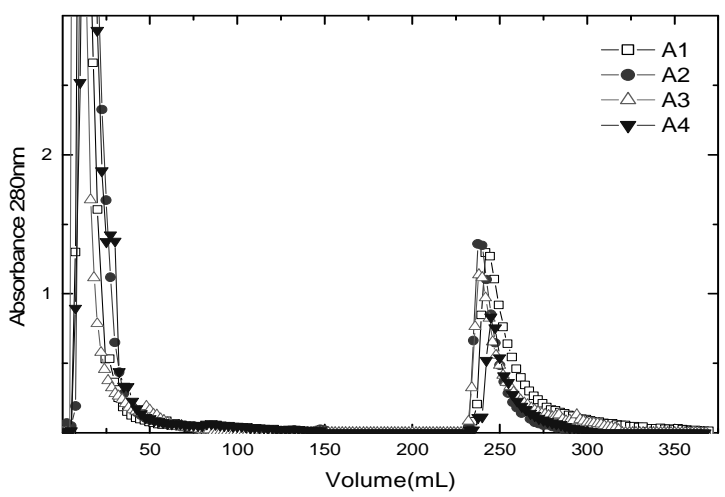

Figure 1 - Affinity chromatography of A. integrifolia crude extract in C. pulcherrima galactomannans matrices with different amounts of ECH (A group). 


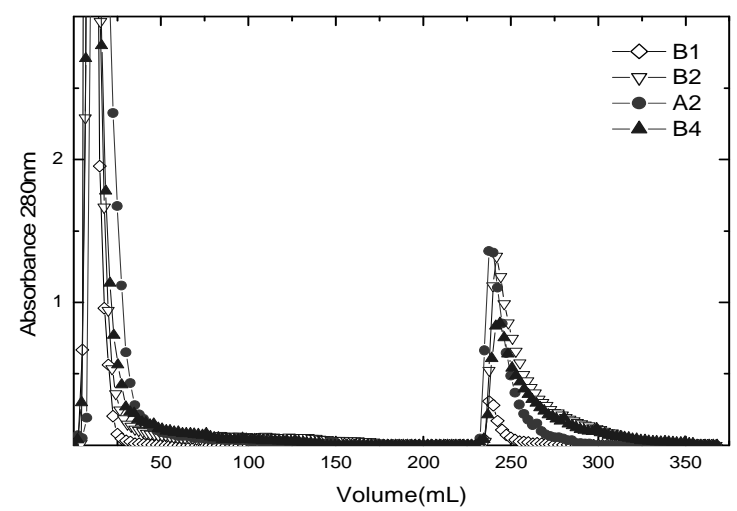

Figure 2 - Affinity chromatography of A. integrifolia crude extract in C. pulcherrima galactomannans matrices with different amounts of $3 \mathrm{M} \mathrm{NaOH}$ (B group).

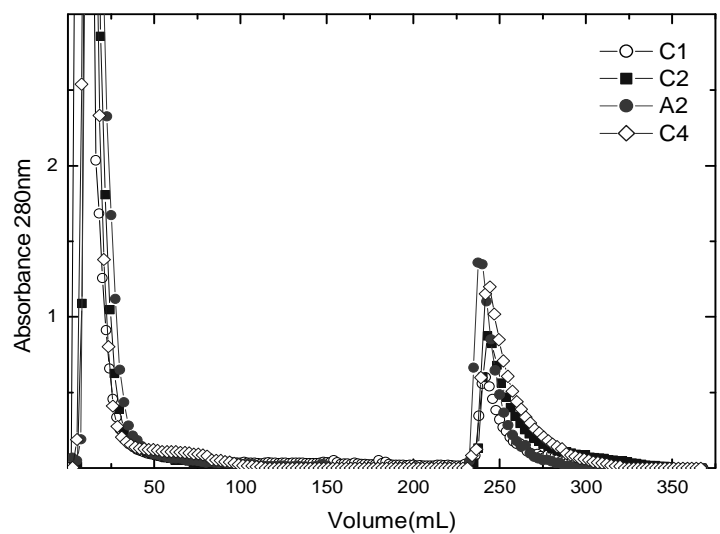

Figure 3 - Affinity chromatography of A. integrifolia crude extract in C. pulcherrima galactomannans matrices with different $\mathrm{NaOH}$ concentrations ( $\mathbf{C}$ group).

Table 5- Ratio of $\mathrm{mg}$ of retained protein (lectin)/g of affinity matrix gel.

\begin{tabular}{ccc}
\hline Tratament & A. integrifolia & A. incisa \\
\hline $\mathrm{A}_{1}$ & 149.0 & 22.0 \\
$\mathrm{~A}_{2}$ & 104.0 & 18.2 \\
$\mathrm{~A}_{3}$ & 111.3 & 3.2 \\
$\mathrm{~A}_{4}$ & 65.4 & 5.7 \\
$\mathrm{~B}_{1}$ & 12.3 & 3.7 \\
$\mathrm{~B}_{2}$ & 153.5 & 5.2 \\
$\mathrm{~B}_{4}$ & 112.6 & 4.6 \\
$\mathrm{C}_{1}$ & 57.4 & 7.0 \\
$\mathrm{C}_{2}$ & 101.8 & 7.4 \\
$\mathrm{C}_{4}$ & 134.4 & 9.1 \\
\hline
\end{tabular}

The $\mathrm{B}_{1}$ matrix showed the weakest results. The volume of $\mathrm{NaOH}$ was insufficient to promote the homogenization and the concentration of gum and $\mathrm{ECH}$ in the reaction medium were too high. This matrix was very compact $(124.4 \mathrm{mg} / \mathrm{mL})$ and with little interaction.

The other columns from group $\mathrm{B}_{1}$ seemed to have similar pattern. The $\mathrm{C}$ group columns showed the same behaviour. This indicated that the concentration of $1 \mathrm{M} \mathrm{NaOH}$ was sufficient to proceeds with the cross-linking reaction.

The results with exudated gums (Lima et al., 2002; Teixeira, 2007) tended to be highly dependent on the $\mathrm{NaOH}$ concentration, but this was not observed with the galactomannan matrices. The likely reason for this was the fact that galactomananns 
were neutral polysaccharides, while exudates gums had acid groups, thus the $\mathrm{NaOH}$ not only solubilized the gum, but also neutralized it.
Figure 4 shows a chromatographic profile for $A$. incisa extract with the matrices that showed the best results matrices with $A$. integrifolia extract.

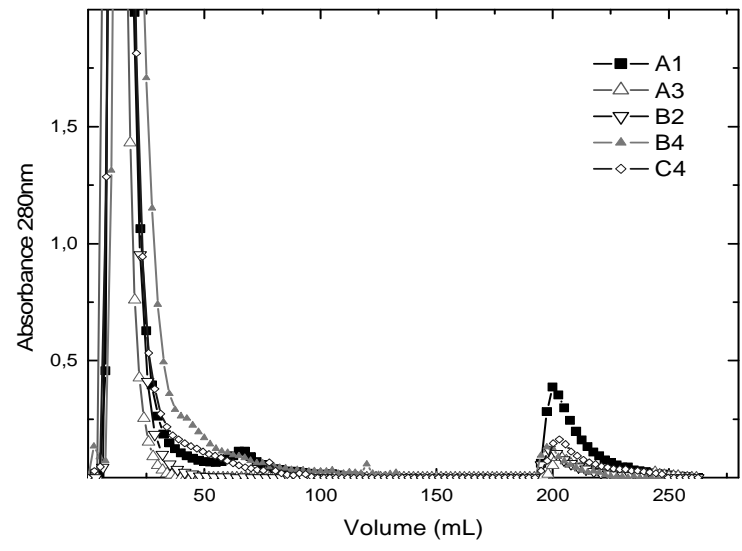

Figure 4 - Affinity chromatography of A. incisa crude extract in C. pulcherrima galactomannans matrices with best results for isolate $A$. integrifolia galactose-binding lectin.

The ratio of $\mathrm{mg}$ lectin/g gel used showed the high efficiency of the $C$. pulcherrima to isolate $A$. integrifolia galactose-binding lectin. The value was nearly of 5-times higher than those obtained by Teixeira et al. (2007), but the interaction with $A$ incisa was similar.

Comparing the profiles in Figures 1, 2, 3, 4 and the data in Table 5, it could be concluded that the treatment $\mathrm{A}_{1}$ (final concentration: $6.0 \mathrm{mmol} / \mathrm{g}$ $(\mathrm{ECH} /$ gum) and $2.8 \mathrm{M}$ of $\mathrm{NaOH}$ ) gave the best results for galactose lectin isolation. This concentration was different from that suggested by Garros-Rosa et al. (2006), Lima et al. (2002) and
Seshagirirao et al. (2005). Garros-Rosa et al. (2006) and Moreira et al. (1998) using matrices with a higher final concentration of ECH $\left(\mathrm{A}_{2}\right.$ formulation). Seshagirirao et al. (2005) used less $\mathrm{ECH}$, with a large quantity of gum $(60 \mathrm{~g})$. The interesting point was the observation that the cross-linking reactions starting with more than $1 \mathrm{~g}$ of gum seemed to be less efficient, and not homogeneous.

The purified gum was used to obtain a new matrix with the $\mathrm{A}_{1}$ formulation to evaluate its ability to bind different plant galactose-especific lectins (Fig $5)$.

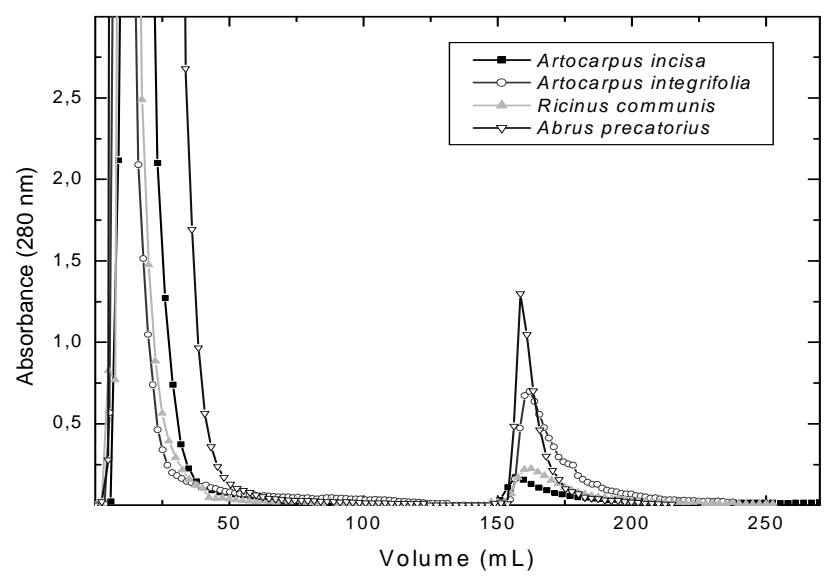

Figure 5 - Affinity chromatography using crude extract of different species, through A1 column.

The presence of lectin in all the fractions (retained and un-retained peaks) was confirmed by the hemagglutination assay (Moreira and Perrone,
1977). The retained peaks showed greater interaction, for example, the hemagglutinating activity shown by the un-retained peak using $A$. 
integrifolia and A. incisa seeds extracts was 128 hemagglutination units $\left(\mathrm{H} . \mathrm{U} \mathrm{mL}^{-1}\right)$. In the retained peaks, the results for hemagglutination were 356 $\mathrm{HUmL}^{-1}$. The higher activity of the un-retained peak showed that all ligand sites in the galactomannans matrices were occupied and that the retained peak represented maximal capacity of the matrices.

The best interaction obtained for jacalin (Artocarpus integrifolia lectin) was $79.7 \mathrm{mg}$ of retained protein $/ 1 \mathrm{~g}$ of dry gel. In the case of Abrus precatorius lectin, $47.2 \mathrm{mg}$ were retained by the column (1g), while the lectins from Ricinus communis and Artocarpus incisa showed less interaction $(17.7 \mathrm{mg}$ and $11.5 \mathrm{mg})$.

These results could be of great interest since the $A$. precatorius lectin showed a strong interaction with $\mathrm{A}_{1}$ gel. Different results were obtained by GarrosRosa et al. (2006). The amount of lectin retained by the column and the activity confirmed by hemaglutination seemed to be unusual. The SDSPAGE electrophoresis demonstrated an excellent purification of the crude extract in a single-steep procedure (Figure 6).

Another point to note was the behavior with the Artocarpus galactose-binding lectins. The $A$. incisa and $A$. integrifolia lectins gave two completely distinct profiles. This was unexpected, since these lectins have similar compositions and structures. The galactomanann matrices used by Moreira et al. (1998) and Garros-Rosa et al. (2006) demonstrated greater interaction with the $A$. incisa than the $C$. pulcherrima matrices. This could be due to the galactose distribution, and the galactose/manose ratio. The purification of these lectins can be seen in Figure 7. The procedure was carried out in only one step, which was shown to be very effective.

When glucose/mannose-binding lectins from Canavalia brasiliensis and Dioclea altissima were tested in the A1 matrix, they were not retained, showing the specificity for galactose-binding lectins.

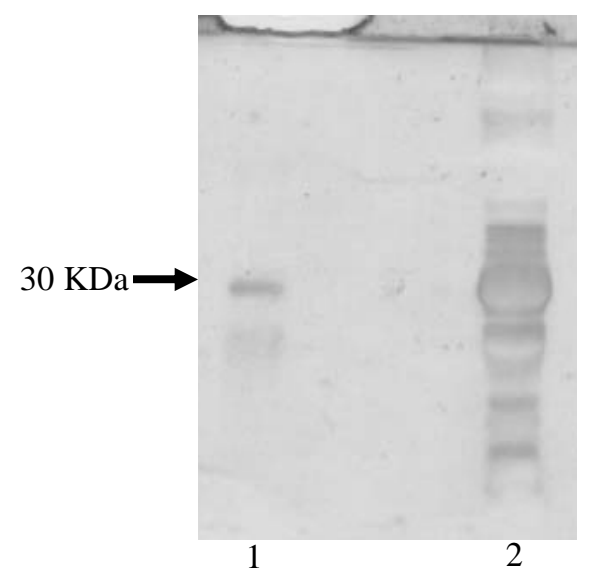

Figure 6 - SDS-PAGE: Line 1 retained peak from A. precatorius chromatography in $C$. pulcherrima column Line 2 crude extract of $A$. precatorius.

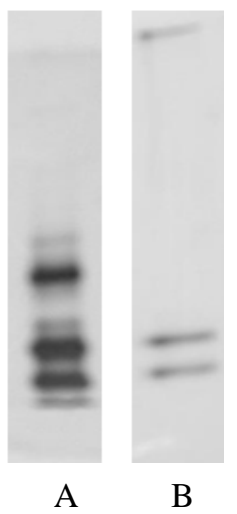

Figure 7 - SDS PAGE: The retained peaks of A. incisa (A) and A. integrifolia (B) extracts in $C$. pulcherrima matrix 


\section{Application}

The $C$. pulcherrima galactomannans matrices were efficient in isolating galactose-binding lectins. These matrices could be used repeatedly without losing their capacity. The same matrix was used in this work for over a year with similar results. This indicated that the galactomannans could be an excellent crude material for matrices to isolate galactose binding lectins. Given the importance of glycoconjugates in many biological interactions, the development of carbohydrate-based technologies (or glycotechnologies) has been intensively pursued (Lima et al., 2002).

The matrices here described were observed to be of high specificity, easy application and low cost. The unsurpassed ability of the sugar code (glycocode) to store biological information in short oligomers is crucial to its role as the third dimension of molecular biology. The sequential distribution and the $M / G$ ratio makes the galactomannans intelligent tools for studies on lectin-glyconjugate interaction and to gain a better understand of glycobiology.

\section{ACKNOWLEDGEMENTS}

The authors are grateful to Departamento de Química Orgânica e Inorgânica, Universidade Federal do Ceará, for IR analysis and to FUNCAP, CNPq and PROCAD/CAPES who was supported this research.

\section{REFERENCES}

Agrawal, B.L. and Goldstein, I.J. (1965) Specific binding of concanavalin A to cross-linked dextran gels. Biochem. J., 96, 23-25.

Alanis, A. D.; Calzada, F.; Cervantes, J. A.; Torres, J.; Ceballos, G. M. (2005). Antibacterial properties of some plants used in Mexican traditional medicine for treatment of gastrointestinal disorders. $J$. Ethnopharmacol, 100, 153-157.

Andrade, C. T.; Azero, E. G.; Luciano, L.; Gonçalves, M. P. (1999) Solution properties of galactomannans extrated from the seeds of Caesalpinia pulcherrima and Cassia javanica: comparison with locust bean gum.) Int. J. of Biol. Macromol., 26, 181-185.

Appukutan, P. S. Surolia, A.; Bachhawat, B. K. (1977), Isolation of two galactose-binding proteins from Ricinus communis by affinity chromatography. Indian J. Bioche. Bio., 14, 382-384.
Azero, E. G. and Andrade, C. T. (2002) Testing procedures for galactomannan purification. Polym. Test., 21, 551-556.

Blum, H., Beier, H., and Gross, H. J. (1987). Improved silver stainin of plant proteins, RNA and DNA, Electrophoresis, 8, 93-99.

Chiang, L. C.; Chiang, W.; Liu, M. C.; Lin, C. C. (2003) In vitro antiviral activities of Caesalpinia pulcherrima and its relates flavonoids. J. Antimicrob. Chemoth., 52, 194-198.

Chowdhury, B.; Chatterjee, B. P., (1987) Purification of a galactomannan from seeds of poinciana pulcherrima linn. using jackfruit lectin immobilized affinity adsorbent and its strutural characterisation. Indian J. Chem. B, 26B, 637-641,.

Fujita, Y. Oishi, K. Suzuki, K. and Imahori, K. (1975). Purification and properties so an anti-b hemagglutinin produced by Streptomyces sp. Biochemistry 14; 20, 4465-4470.

Garros-Rosa, I., Reicher, F., Petkowicz, C. L. O., Sierakowski, M. R., et al. (2006). Characterization of the Galactomannans from Parkinsonia Aculeata Seeds and their Application on Affinity Chromatography. Polímeros Ciência e Tecnologia, 16, 99-103.

Glavechev, I., Sirashki, G. and Mateva, R. (2000) Characterization of polyepichlorochydrin and copolymers of epichlorohydrin-glycidyl ethers by IR spectroscopy. Polym. Test., 19, 415-417.

Laemmli, U. K. (1970). Cleage of strutural proteins during the assembly of the head of bacteriophage Nature, 227, 680-685.

Lima, R. S. N.; Lima, J. R.; Salis, C. R.; Moreira, R. A.(2002) Cashew-tree (Anacardium occidentale L.) exudate gum: a novel bioligand tool. Biotechnol. Appl. Biochem., 35, 45-53.

Moreira, R. A. and Perrone, J. C. (1977). Purification and partial characterization of a lectin from of Phaseolus vulgaris. Plant Physiol., 59, 783-787.

Moreira, R. A., Castelo-Branco, C. C., Monteiro, A. C. O., Tavares, R. O., and Beltramini, L. M. (1998). Isolation and Partial Characterization of A Lectin From Artocarpus Incisa L. Seeds. Phytochemistry, 47, 1183-1188

Nangia-Makker, P., Conklin, J., Hogan, V., Raz, A. (2002), Carbohydrate-binding proteins in cancer, and their ligands as therapeutic agents. TRENDS in Molecular Medicine, 8, 187-192.

Owens, S. J.; Prychid, C.; Cox, A. V. (1995) . Structure and development of the stigma, style and ovary of Caesalpinia pulcherrima (L.) Sw., post-anthesis, preand post-pollination. Bot. J. Linn. Soc. 118, 275-288.

Patil, A. D.; Freyer, A. J.; Webb, R. L.; Zuber, G.; Reichwein, R.; Bean, M. F.; Faucette, L.; Johnson, R. K,(1997) Pulcherrimins A-D, Novel Diterpene Dibenzoates from Caesalpinia pulcherrima with Selective Activity against DNA Repair-Deficient Yeast Mutants. Tetrahedron, 53:5, 1583-1592. 
Prakash, D.; Niranjan A.; Tewari S. K.; (2001) Pushpangadan P. Underutilised legumes: potential sources for low-cost protein. Int. J. Food Sci. Nutr., 52: 4, 337-341.

Seshagirirao, K., Leelavathi, C., and Sasidhar, V. (2005). Cross-linked Leucaena Seed Gum Matrix: An Affinity Chromatography Tool for Galactose-specific Lectins. J. Biochem. Mol. Biol., 38, 370-372.

Souza, M. A., Amâncio-Pereira, F., Cardoso,C. R. B., Silva, A. G., Silva, E. G., Andrade, L. R., Pena, J. D. O., Lanza, H., Afonso-Cardoso, S. R. (2005) Isolation and Partial Characterization of a D-GalactoseBinding Lectin from the Latex of Synadenium carinatum, Braz. Arch. Biol. Techn. 48:5,705-716.

Srivasta, M and Kapoor, V. P. (2005) Seed Galactomnnans: An Overview. Chemistry and Biodiversity, 2, 295-317.
Teixeira, D. M. A., Braga, R. C., Horta, A. C. G., Moreira, R. A., Brito, A. C. F. de, Maciel,, J. S., Feitosa, J. P. A., de Paula, R. C.M. (2007) Spondias purpurea Exudate polysaccharide as affinity matrix for the isolation of a galactose-binding-lectin. Carbohydrate Polymers, 70, 369-377.

Teixeira, S. P. and Machado, S. R. (2008) Storage sites in seeds of Caesalpinia echinata and $C$. ferrea (Leguminosae) with considerations on nutrients flow. Braz. Arch. Biol. Techn. 51: 1, 127-136.

Triebold H.O.,(1946) Quantitative Analysis with Application on Agriculture and Food Products. D. Van Nostrand Co., New York.

Vasconcelos, I. M.; Oliveira, J. T. A. (2004) Antinutritional properties of plant lectins. Toxicon, $15 ; 44: 4,385-403$ 